\title{
Habitat-Distribution Modeling of a Recolonizing Black Bear, Ursus americanus, Population in the Trans-Pecos Region of Texas
}

\author{
Mindy B. Rice ${ }^{1,4}$, WARren B. Ballard ${ }^{1}$, Ernest B. Fish ${ }^{1}$, NANCy E. McInTyre ${ }^{2}$, and David \\ HOLDERMANN $^{3}$ \\ ${ }^{1}$ Texas Tech University, Department of Natural Resources Management, Box 42125, Lubbock, Texas 79409 USA \\ ${ }^{2}$ Texas Tech University, Department of Biological Sciences, Box 43131, Lubbock, Texas 79409 USA \\ ${ }^{3}$ Texas Parks and Wildlife, Trans-Pecos District 1, 109 South Cockrell, Alpine, Texas 79830 USA \\ ${ }^{4}$ Present address: Colorado Division of Wildlife, 317 W. Prospect Street, Fort Collins, Colorado 80526 USA
}
Rice, Mindy B., Warren B. Ballard, Ernest B. Fish, Nancy E. McIntyre, and David Holdermann. 2009. Habitat-distribution modeling of a recolonizing Black Bear, Ursus americanus, population in the Trans-Pecos region of Texas. Canadian Field-Naturalist 123(3): 246-254.

Black Bears (Ursus americanus) were once widespread across Texas, but their numbers were reduced in the early 1900 s. Recolonization of the Trans-Pecos region of Texas has occurred via bears migrating northward from Mexico. Recent bear sightings have increased in this area. This could be an indication that the population in Texas is beginning to recover, but the population will continue to expand only if there is suitable habitat to occupy. To help identify suitable habitat and restoration areas, we developed a predictive habitat-distribution model by using records of Black Bear sightings from 1996 to 2003 to map the species' distribution. Using Bayesian statistics, we modeled the probability of occurrence of Black Bears in the Trans-Pecos region based on sighting locations. We used GIS layers for land use/landcover, elevation, water sources, and road networks to obtain covariates in our modeling. We used a 10-fold cross-validation to test the effectiveness of using sighting data. Our results indicated a negative association with bare areas, agriculture, and grassland landcovers. In addition, southern aspect, elevation, distance to water, slope, and western aspect also influenced suitable habitat. Both the original and validation datasets correctly classified bear sightings $93.9 \%$ and $93.7 \%$ of the time, respectively. Our model can be used to target restoration efforts to enhance the ability of the Black Bear to expand in the Trans-Pecos region. It can also identify private landowners most likely to be affected by the expansion of Black Bears for education and cooperative efforts.

Key Words: Black Bear, Ursus americanus, Bayesian statistics, GIS, habitat prediction map, restoration, Trans-Pecos, Texas.

Black Bears (Ursus americanus) were reportedly widespread across Texas in the 1800 s, but by the early 1900s their numbers had been reduced by overhunting, predator control, and loss of habitat (Onorato and Hellgren 2001; Whittaker and Burns 2001). By 1960, no Black Bears remained in Texas. In the early 1980s, a small bear population in northern Mexico served as a source population for natural recolonization of the Trans-Pecos region, and in 1987 Texas declared the Black Bear endangered (Onorato et al. 2003). There are now repeated sightings of Black Bear in the Dead Horse, Glass, Del Norte, Davis, and Guadalupe mountains, suggesting that bears may continue to expand their distribution into other parts of the Trans-Pecos (Figure 1; Onorato et al. 2003). The population size in Texas increased in the 1990s to an estimated 30-50 individuals, which resulted in a status change to threatened in 1996 (Whittaker and Burns 2001).

Four factors have likely contributed to the expansion of Black Bears in this region: (1) increased tolerance by humans of Black Bears, (2) legal protection of bears, (3) the existence of unoccupied woodland in Texas, and (4) the presence of a source population in Mexico (Onorato and Hellgren 2001; Kamler et al. 2003). Although research has been conducted on this population in Mexico and in Big Bend National Park, Texas (Doan-Crider 1995; Mitchell et al. 2002), there has been no regional analysis of potential suitable habitat for expansion. Knowledge of the extent, spatial arrangement, and connectivity of suitable habitat is required to allow the possible colonization of unoccupied habitat to be predicted (Schadt et al. 2002). This is the first step in a regional restoration effort of a formerly extirpated Black Bear population.

Ecological restoration can occur within the context of regional landscape-level planning and design (Harris et al. 2001). One way to accomplish this is to build a model from environmental data and known locations of a focal species to predict the distribution of suitable habitat for the species (Guisan and Zimmermann 2000). Where data on population distribution and abundance are unavailable, detailed sighting information can be especially useful. Much of the information on Black Bears in the Trans-Pecos is available via conversations with locals (Onorato and Hellgren 2001) or sighting data collected by Texas Parks and Wildlife. The data include radiolocations, road kills, observations by biologists, and some reports made by members of the public. Sighting data have been used successfully to model habitat suitability for Lynx [Lynx canadensis] (Palma et al. 1999), Grizzly Bear [Ursus arctos horribilis] (Agee and Stitt 1989), Bobcat [Lynx rufus] (Woolf et al. 2002), and Mountain Lion [Puma concolor] (Pike et al. 1999). 

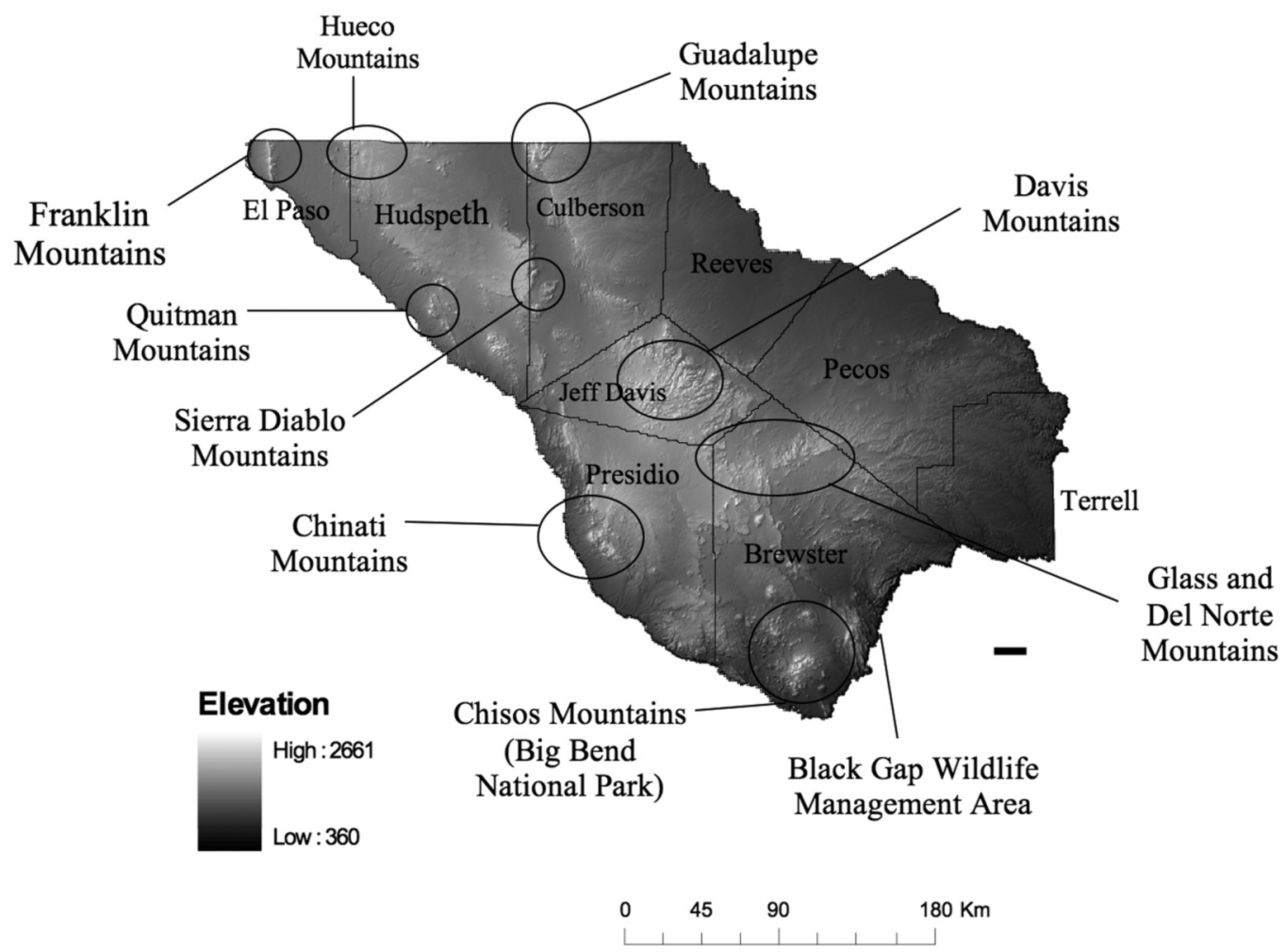

FIGURE 1. Map of the nine counties in the Trans-Pecos region of Texas with identified mountains ranges.

Although there are few cases of large carnivores naturally recolonizing an area, recolonization by Wolves [Canis lupus] in North America and Europe, by Brown Bears [Ursus arctos arctos] in Scandinavia, and by Black Bears in Oklahoma (Bales et al. 2005) indicates that the right conditions can exist. To understand whether an area can support increasing populations of vertebrates, it is imperative to understand the suitability of an area as habitat for a species (Queheillalt and Morrison 2006). Our objective for this study was to identify the potential expansion range of the Black Bear in the Trans-Pecos region based on potential habitat suitability. This will be a first step in providing wildlife managers with a comprehensive analysis of available Black Bear habitat to use in the development of a Black Bear management plan in western Texas.

\section{Methods}

Study Area

Due to its proximity to Black Bear habitat in Mexico and possibly New Mexico (Onorato et al. 2004), the 7.7 million ha Trans-Pecos region of Texas represents a large tract of potentially suitable habitat for bear recolonization. The region is made up of nine counties in Texas and constitutes about $11 \%$ of the state. The environment in the Trans-Pecos is unique compared to other Black Bear habitat across the United States, since the lower elevations are part of the Chihuahuan Desert, the largest desert in North America (Powell 1998). This community is characterized by leaf succulent and semi-succulent plants that typically grow on exposed mountainsides and canyon walls (Gehlbach 1981). The area receives 30.5 to $45.7 \mathrm{~cm}$ of rain per year (Casey 1972; Steele 1998), and almost all the plants in the area have adaptations to conserve water. The mountains of the Trans-Pecos create a series of island woodland habitats (considered typical habitat for Black Bears) separated by sometimes inhospitable desert vegetation (Powell 1998). Elevations range from 2000 feet along the Rio Grande to more than 7000 feet in the high Chisos Mountains (Steele 1998).

\section{Sighting Data}

We gathered sighting data dating from 1903 to 2003 from Big Bend National Park, Guadalupe Mountain National Park, and the Texas Parks and Wildlife Department. There were a total of 3675 sightings from all nine counties of the Trans-Pecos region (Figure 1). All sight- 
ings were rated as class 1 or class 2 sightings, which indicate that a bear is in possession, there is tangible evidence documented, or it has been reported by an experienced and reliable witness. To account for the potential lack of independence in the data, we eliminated all sightings that occurred within the same month of the same year within a $5 \mathrm{~km}$ radius of any other sighting. We used sightings from only 1996 to 2003 for model development because we assumed that the landscape had changed over the past century and we wanted to use the most current data to model the nearterm future expansion of the population. In addition, the data used to build the GIS environmental layers came from information gathered from 1997 to 2002 , so our intent was to match the GIS database to the sighting data.

\section{Landcover Variables}

We selected potential covariates based on previous studies of Black Bears in New Mexico, Texas, and Mexico. Steep slopes, rock, and higher elevations were common settings for den placement by Black Bears in Big Bend National Park, so we included these three covariates (Mitchell et al. 2005). Disturbed areas such as roads and urban areas (mostly because of the attraction provided by trash) were important in Texas, so we included distance to roads, cropland, and urban habitats to account for these disturbed areas (Hellgren et al. 1991; Onorato et al. 2003). Two studies in other jurisdictions found that bears favored areas near water, so we included distance to water sources in our model (Garshelis and Pelton 1981; LeCount and Yarchin 1990). Woodland and sotol (Dasylirion wheeleri) shrublands were found to be important landcovers for resource and food selection by Black Bears in this region (Hellgren 1993), so we included the availability of these landcover types as candidate variables.

We initially considered 15 variables for the model: elevation, aspect (south, west, north, and east), slope, distance to water, distance to roads, proportion of bare ground, proportion in agriculture, proportion of shrubland, proportion of grassland, proportion of wetland, proportion of woodland, and proportion of urban. Due to the lack of buffers containing wetland for both bear and random locations, we withheld the proportion of wetland variable from the model (Boccadori et al. 2008; Ciarniello et al. 2007).

We applied a $2.2 \mathrm{~km}$ radius around each bear record based on the average daily linear movement of female Black Bears from previous analyses (Feckse et al. 2003; Rice 2006). The average daily movement of females has been used in other studies of large carnivores to buffer a point location (Carroll and Miquelle 2006). An equal number of random sightings was obtained using Hawth's tools in ArcGIS 9.0 (Beyer $2004 *)$, and these were considered "absence" sighting points $(n=2079)$. Pseudo-absences are meant to provide a comparative data set to enable the conditions under which a species occurs to be contrasted to where it is absent (VanDerWal et al. 2009). Based on findings that woodland is a significant predictor of bear habitat in this region (Onorato et al. 2003; Mitchell et al. 2005) and that $65 \%$ of our bear locations were located in the woodland landcover, we restricted the pseudo-absence point locations to woodland landcover (Poirazidis et al. 2004). Therefore, the proportion of woodland variable was not included in the model. The same $2.2 \mathrm{~km}$ buffer was applied to the pseudo-absence points, but we did not allow any overlap between bear sighting buffers and the pseudo-absence buffers (Poirazidis et al. 2004).

We derived environmental variables used in the model from relevant GIS layers. We obtained elevation data from the National Elevation Dataset from the U.S. Geological Survey for the elevation layer (resolution $=30 \mathrm{~m}$ ). We then derived the slope and aspect layers using the Spatial Analyst extension in ArcGIS. We generated the landcover/land use layer from 10 Landsat images using ERDAS software that classified seven landcover/land use values (resolution $=30 \mathrm{~m}$; Rice 2006). This layer was ground truthed and found to be $75 \%$ accurate (Rice et al. 2008). We used the National Hydrography Dataset to generate hydrology layers and determined the distance from each sighting and random point to the nearest water source. We obtained road data from the Texas Department of Transportation and calculated the distance from each sighting and random point to the closest road.

\section{Statistical Analysis}

We summarized all pixel values for each variable in each bear location buffer using the average and we repeated this process for the random sighting buffers. These variables were then centered by subtracting the mean for all buffers from each individual buffer to improve the efficiency of the Markov chain Monte Carlo algorithm by generating posterior samples with lower autocorrelation (McCarthy 2007). We used a generalized linear regression in the Bayesian framework using WinBUGS (Version 1.4; Spiegelhalter et al. 2003*). The Bayesian approach incorporates prior knowledge and provides an interval within which the parameter value lies (O’Neill et al. 1988). We assumed no pre-existing knowledge of model coefficients. This resulted in the use of non-informative prior distributions for all variables (O’Neill et al. 1988; MacNally et al. 2004), meaning that our data dictate the posterior probability distributions (MacNally et al. 2004). Non-informative priors also reduce the risk of choosing a subjective distribution and make all parameters equally likely (Wintle et al. 2003). WinBUGS takes samples from the posterior distribution by using a Markov chain Monte Carlo sample (McCarthy 2007). We used three chains, each with a burn-in period of 1000 iterations followed by 50000 iterations for estimation. An assumption of Bayes theorem is that predictor variables must be independent (Tucker et al. 1997). Therefore, we calculated correlations and if the 

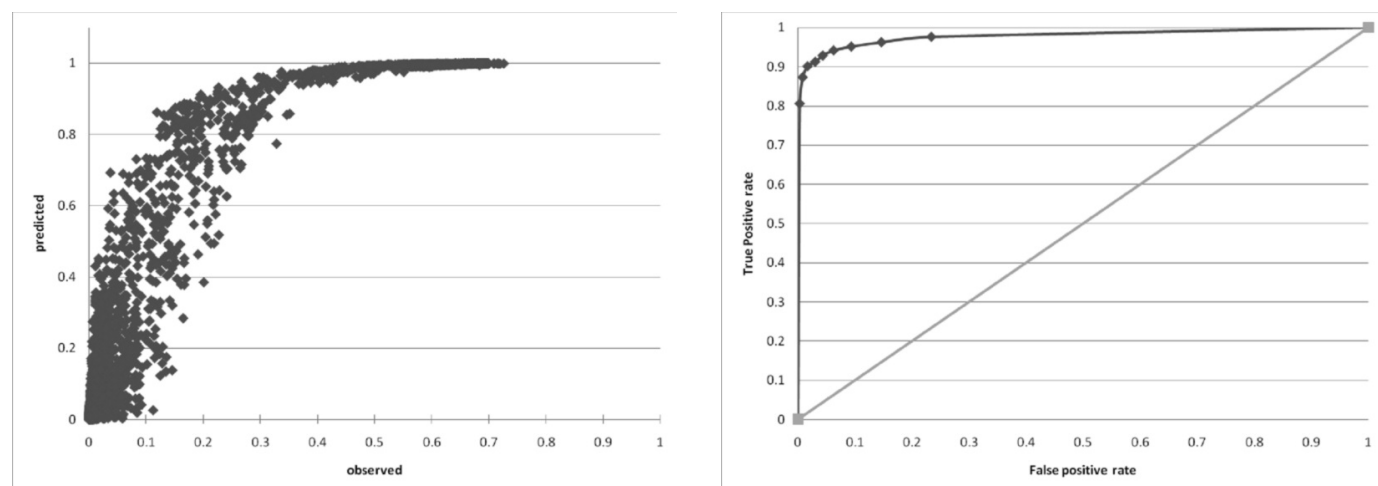

FIGURE 2. Validation procedures: (a) predicted values from the top model beta coefficients compared to the observed values from the original Black Bear locations; and (b) area under the receiver operating characteristic (ROC) curve, plotting sensitivity (true positives) vs. 1-specificity (false positives) for bear location predictions based on 10 threshold values from 0 to 1 in the Trans-Pecos region of Texas.

correlation was $>0.6$ we removed those variables, which were deemed less important. This resulted in the removal of proportion of urban, proportion of shrubland, north aspect, and east aspect, resulting in 9 candidate variables for modeling.

We tested 10 models based on variable combinations found to be influential in previous studies. We chose the best model based on the deviance information criterion (DIC), the Bayesian equivalent of the Akaike Information Criterion (McCarthy 2007). The top model was the one with the lowest DIC score. We entered the resulting equation into ArcGIS using the raster calculator. We used the exponential function in the raster calculator of ArcGIS to calculate the following logit function:

$$
\frac{e^{\left(\beta_{0}+\beta_{1} X_{1 i}+\ldots+\beta_{k} X_{k i}\right)}}{1+e^{\left(\beta_{0}+\beta_{1} X_{1 i}+\ldots+\beta_{k} X_{k i}\right)}}
$$

where $\beta=$ parameter estimates, $X=$ explanatory variables, and $\mathrm{k}=$ number of variables. This resulted in a probability layer with values ranging from 0 to 1 . The probability of suitable bear habitat was assessed by comparing the predicted and the observed probabilities to determine an appropriate cut-off threshold.

We used a variety of validation procedures, as we did not have an independent data set to use for comparison purposes. For the top model, we evaluated the classification rates using Cohen's kappa at both the standard (0.5) and optimal probability (determined from Figure 2) cut-off points (Slauson et al. 2007). The Cohen's kappa statistic measures the proportion of bear locations and random locations predicted correctly after accounting for chance. We then evaluated the area under the receiver operating characteristic (ROC), which provides a single measure of overall accuracy not dependent on a particular threshold (Graf et al. 2007). We plotted sensitivity (the probability that a model correctly classifies bear locations) versus 1specificity (the probability that a model will incorrectly classify random locations) over a range of probability thresholds from 0 to 1 (Lantz et al. 2007).

Finally, we assessed the predictive capability of the top model based on a 10-fold cross-validation procedure (Boyce et al. 2002). We estimated the Bayesian model using a random draw of $90 \%$ of the data and used this model to predict the frequency of occurrence in the withheld 10\% (Ciarniello et al. 2007). We used a Spearman rank correlation to assess the relationship between predicted occurrence for the withheld locations and their frequency within 10 equally sized classes of values from 0 to 1 (Johnson et al. 2005). To account for variation in the area covered by each category of resource selection function (RSF) bin on the landscape, we used an area adjusted frequency by dividing the 10 bins by the area covered by that range of scores (Boyce et al. 2002). A model with a higher $R^{2}$ value is considered to be a good predictor (Long et al. 2009).

\section{Results}

The elimination of multiple sightings resulted in a total of 3177 sightings overall and 2079 sightings from 1996 to 2003 for model development. The best fitting model (smallest DIC value) consisted of the full model with all variables included (Table 1). The second best model did not include the southern or western aspects, but it was not a real competitor with the top model (Table 1).

The top model indicated that bear sightings were negatively associated with bare landcover, agriculture, grassland, elevation, the southern aspect, and distance 
TABLE 1. Ranking results for models of habitat suitable for Black Bears developed in the Trans-Pecos region of Texas.

\begin{tabular}{|c|c|c|c|}
\hline Model $^{1}$ & $\begin{array}{c}\text { Mean } \\
\text { deviance }\end{array}$ & $\begin{array}{c}\text { Deviance } \\
\text { information criterion }\end{array}$ & $\mathrm{pD}^{2}$ \\
\hline $\bar{a} \cdot \mathrm{g} \cdot \mathrm{b} \cdot \mathrm{e} \cdot \mathrm{sl} \cdot \mathrm{st} \cdot \mathrm{w} \cdot \mathrm{rdd} \cdot \mathrm{wtd}$ & 1351.085 & 1360.883 & 9.798 \\
\hline $\mathrm{a} \cdot \mathrm{g} \cdot \mathrm{b} \cdot \mathrm{e} \cdot \mathrm{sl} \cdot \mathrm{rdd} \cdot \mathrm{wtd}$ & 1378.919 & 1386.767 & 7.848 \\
\hline $\mathrm{a} \cdot \mathrm{g} \cdot \mathrm{b} \cdot \mathrm{e} \cdot \mathrm{st} \cdot \mathrm{rdd} \cdot \mathrm{wtd}$ & 1680.391 & 1688.365 & 7.974 \\
\hline $\mathrm{a} \cdot \mathrm{g} \cdot \mathrm{b} \cdot \mathrm{rdd} \cdot \mathrm{wtd}$ & 1684.494 & 1690.404 & 5.91 \\
\hline $\mathrm{a} \cdot \mathrm{g} \cdot \mathrm{b} \cdot \mathrm{e} \cdot \mathrm{rdd} \cdot \mathrm{wtd}$ & 1685.521 & 1692.444 & 6.923 \\
\hline $\mathrm{a} \cdot \mathrm{g} \cdot \mathrm{b} \cdot \mathrm{e} \cdot \mathrm{st} \cdot \mathrm{wtd}$ & 1798.997 & 1805.963 & 6.966 \\
\hline $\mathrm{a} \cdot \mathrm{b} \cdot \mathrm{e} \cdot \mathrm{sl} \cdot \mathrm{st}$ & 1842.076 & 1847.801 & 5.725 \\
\hline $\mathrm{a} \cdot \mathrm{g} \cdot \mathrm{b} \cdot \mathrm{e} \cdot \mathrm{st}$ & 1939.222 & 1945.141 & 5.919 \\
\hline $\mathrm{a} \cdot \mathrm{g} \cdot \mathrm{b}$ & 1945.761 & 1949.682 & 3.921 \\
\hline $\mathrm{a} \cdot \mathrm{b} \cdot \mathrm{e} \cdot \mathrm{st}$ & 3359.408 & 3364.387 & 4.979 \\
\hline
\end{tabular}

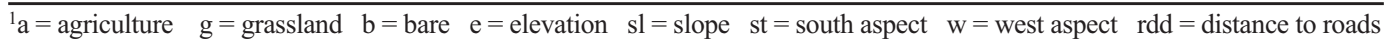
$\mathrm{wtd}=$ distance to water

${ }^{2} \mathrm{pD}$ is the effective number of variables in the model

TABLE 2. Estimated posterior distribution coefficients for the top model based on Bayesian estimation, standard deviation, and $95 \%$ credible intervals for habitat suitable for Black Bears in the Trans-Pecos region of Texas.

\begin{tabular}{lccc}
\hline \hline Parameter & $\begin{array}{c}\text { Mean of } \\
\text { posterior distribution }\end{array}$ & $\begin{array}{c}\text { Standard } \\
\text { deviation }\end{array}$ & $\begin{array}{c}95 \% \text { credible } \\
\text { interval }\end{array}$ \\
\hline Proportion of bare & -18.2986 & 4.15 & -27.5728 to -11.2425 \\
Proportion in agriculture & -14.8459 & 3.757 & -21.9755 to -7.5090 \\
Proportion of grassland & -6.62253 & 0.4172 & -7.4820 to -6.6090 \\
Southern aspect & -3.56822 & 0.7074 & -4.9444 to -2.2117 \\
Elevation & -0.00245 & $3.518 \mathrm{E}-4$ & -0.0031 to -0.0019 \\
Distance to water & -0.00109 & $1.591 \mathrm{E}-4$ & -0.0014 to -0.0008 \\
Distance to roads & $7.12 \mathrm{E}-05$ & $8.36 \mathrm{E}-5$ & $-8.65 \mathrm{E}-5$ to 0.0002 \\
Slope & 0.133474 & 0.009943 & 0.1164 to 0.1506 \\
Western aspect & 1.307644 & 0.6151 & 0.1715 to 2.4579 \\
\hline \hline
\end{tabular}

to water (Table 2). Bear sightings were positively associated with slope, the western aspect, and distance to roads. So we would expect suitable habitat not to be located near bare landcover, agriculture, or grassland and to be at lower elevations and closer to water sources. We would also expect suitable habitat to be on steeper slopes and further from roads. Although distance to roads was included in the model, the $95 \%$ credible interval included the value of 0 , which indicates little influence on bear locations (McCarthy 2007). All other variables were significant, as they did not include the value of 0 in their credible intervals. The three landcover types included in the model were the three highest-ranking variables in the model, with bare landcover having the greatest influence.

Based on the observed versus predicted values, a threshold of $>0.4$ probability for suitable habitat prediction is reasonable (Figure 2a). Potentially suitable habitat was mostly located in the mountainous regions of the Trans-Pecos (Figure 3). Considering the entire Trans-Pecos region, a probability value of $>0.4$ accounts for about $25 \%$ of the landscape that contains relatively suitable habitat. Highly suitable habitat with probability values $>0.9$ accounts for about $8 \%$ of the Trans-Pecos region, mostly restricted to the woodland and mountainous areas.
Correct classification (probability cut-off $=0.4$ ) averaged $93.9 \%$ and $93.7 \%$ for the original and crossvalidation datasets, respectively (Table 3a). Cohen's kappa indicated good model performance at both probability cut-offs of 0.5 and 0.4 for the original and validation datasets, respectively (Table 3a). The area under the curve from the model ROC plot indicated that the model correctly distinguished between a bear location and a random location (Figure 2b). All Spearman rank coefficients indicated that all cross-validated datasets were good predictors of suitable bear habitat (Table 3b).

\section{Discussion}

Landcover/land use seems to be the driving influence for the predicted expansion of this Black Bear population. Bear locations were negatively associated with grassland, agricultural areas, and bare patches of landscape. This would reflect the life history of bears and their ties to shrubland and woodland mast crops. In addition, the agricultural areas in this region are limited and are mostly associated with cattle ranches rather than food crops (Onorato et al. 2003).

Currently, the breeding population of Black Bears is located in the 372377 ha of Big Bend National Park and Black Gap Wildlife Management Area. There 


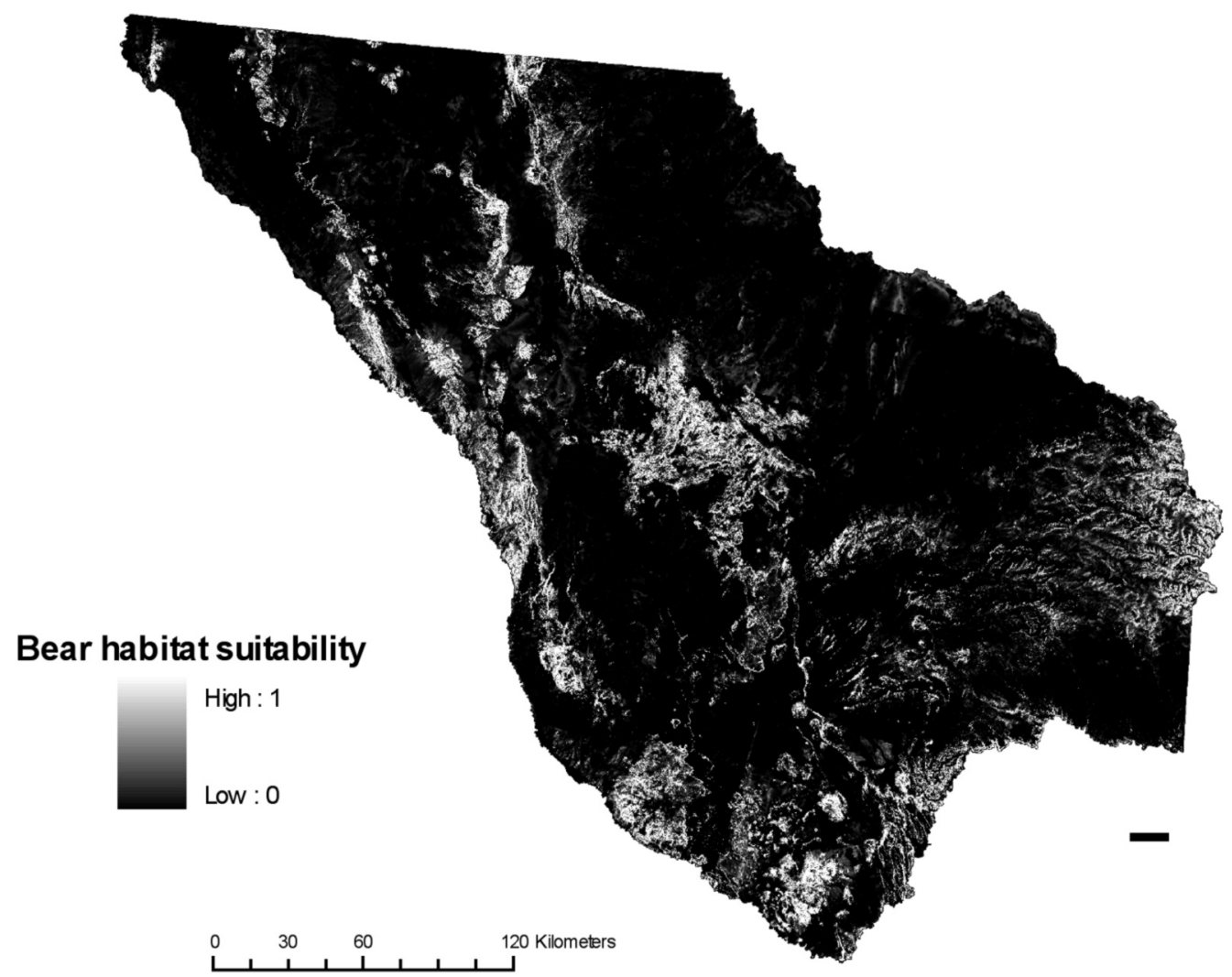

FIGURE 3. A. Comparison of measures for the original model dataset and the cross-validated datasets based on percentage correctly classified, sensitivity, specificity, Cohen's kappa at a threshold of 0.5 , Cohen's kappa at a threshold of 0.4 , and the area under the receiver operating characteristic (ROC) curve. B. Spearman rank correlations $\left(r_{\mathrm{s}}\right)$ between resource selection function (RSF) bin ranks and area-adjusted frequencies for each cross-validated model set.

is a continuous strip of suitable habitat extending from Big Bend National Park and the Black Gap Wildlife Management Area to other suitable habitat patches in the Glass and Del Norte mountains, and this strip may serve as a corridor (Figure 1). The distances from Big Bend National Park to the next two patches of highly suitable habitat are $136.5 \mathrm{~km}$ to the Rio Grande and the Chinati Mountains in Presidio County and $188.1 \mathrm{~km}$ to the Davis Mountains in Jeff Davis County (Figure 1). These are feasible dispersal distances for this population, given that previous studies in the Trans-Pecos found that two females and one male traveled 154, 214, and $178 \mathrm{~km}$, respectively (Hellgren et al. 2005). In addition, this region has a relatively low human population and little development threatening the region's habitats (Onorato et al. 2004). There is also a large percentage of predicted habitat in Hudspeth County in the northern Trans-Pecos region, so Black Bears may be able to expand south from the New Mexico region and Arapahoe National Forest.
Although sighting data have been used in many studies, there is still a stigma attached to such data. How useful are they? Often there is a strong locational bias, with higher sampling rates in the most accessible sites (Davis et al. 1990). There can also be an issue when only a few individuals exist in a population, because this limits the number of independent sightings and lowers the power of statistical inferences (Stoms et al. 1993). Although using sighting data to develop a model of potential habitat has its disadvantages, our validation procedures indicated our model is robust. In addition, the effort and cost involved in a mark-recapture or haircapture study are too high for a region this large. Sighting data provide a useful dataset for investigating the general patterns of a small population across a large region such as the Black Bear in the Trans-Pecos.

Some of the potential habitat lies along the banks of the Rio Grande, which forms the western boundary of the Trans-Pecos in Texas. Riparian areas interspersed with other cover types have been found to be impor- 
TABLE 3. A. Comparison of measures for the original model dataset and the cross-validated datasets based on percentage correctly classified, sensitivity, specificity, Cohen's kappa at a threshold of 0.5 , Cohen's kappa at a threshold of 0.4 , and the area under the receiver operating characteristic (ROC) curve. B. Spearman rank correlations ( $\mathrm{rs}$ ) between resource selection function (RSF) bin ranks and area-adjusted frequencies for each cross-validated model set.

\begin{tabular}{lcc}
\hline \hline A. & & \\
Measure & Original & Validation \\
\hline Correct classification (\%) & 93.9 & 93.7 \\
Sensitivity & 0.925 & 0.924 \\
Specificity & 0.836 & 0.835 \\
Cohen's kappa (0.5 threshold) & 0.885 & 0.881 \\
Cohen's kappa (0.4 threshold) & 0.879 & 0.875 \\
Area under the curve (AUC) & 0.977 & 0.975 \\
\hline
\end{tabular}

B.

\begin{tabular}{cc} 
Set & $\mathrm{r}_{\mathrm{s}}$ \\
\hline 1 & 0.923 \\
2 & 0.939 \\
3 & 0.927 \\
4 & 0.964 \\
5 & 0.939 \\
6 & 0.903 \\
7 & 0.976 \\
8 & 0.915 \\
9 & 0.988 \\
10 & 0.964 \\
Combined & 0.891 \\
\hline \hline
\end{tabular}

tant in other regions (Koehler and Pierce 2003) and may be essential in the desert environment of Mexico and Texas. Our study indicated that Black Bear locations were closer to water sources than random locations, and this could indicate that Black Bears are relying on water resources in this region. With less than $1 \%$ of the original riparian vegetation in the western United States remaining (Queheillalt and Morrison 2006), wildlife managers should consider restoring important water resources within the predicted Black Bear habitat in the Trans-Pecos in cooperation with private landowners. This would provide routes to enable Black Bear expansion if it were to continue into the predicted areas.

The Black Bear has been described as an umbrella species, flagship species, and habitat quality indicator (Dugelby et al. 2001). Maintaining habitat for Black Bears can presumably preserve most other species in the same habitat (Davis et al. 1990). Although restoration usually entails the enhancement or alteration of the environment, the natural recolonization by Black Bears of the Trans-Pecos could provide a different scenario. The normal factors limiting the re-establishment of a population, such as habitat loss, habitat fragmentation, and anthropogenic constraints, are largely absent in this region (Sanderson et al. 2008). Much of the potentially suitable habitat may be occupied by large cattle ranges and privately owned land (Doan-Crider 1995 ) rather than highly populated urban centers. Perhaps the most effective option for the management of this Black Bear population is to preserve habitat in key suitable habitat areas in cooperation with private landowners. In addition, to increase the ability of Black Bears to reach suitable habitat, safe travel for Black Bears that may be dispersing would be essential to any restoration effort. Our prediction map can be used not only to identify potential expansion areas for Black Bears but also to provide managers with a tool for identifying landowners that could be most affected by bear colonization. The continued effort of habitat protection and cooperation with landowners will greatly benefit this small Black Bear population and perhaps enable the natural recolonization of the Trans-Pecos region.

\section{Acknowledgments}

This study was funded by Texas Parks and Wildlife Department and Texas Tech University. We thank K. Searle, M. Morrison, S. McCorqodale, and two anonymous reviewers for comments on previous drafts. This is Texas Tech University College of Agricultural Science and Natural Resources publication T-9-1130.

Documents Cited (marked * in text)

Beyer, H. L. 2004. Hawth's analysis tools for ArcGIS. Available at http://www.spatialecology.com/htools.

Spiegelhalter, D. J., A. Thomas, N. G. Best, W. R. Gilks, and D. Lunn. 2003. BUGS: Bayesian inference using Gibbs sampling. MRC Biostatistics Unit, Cambridge, England. http://www.mrc-bsu.cam.ac.uk/bugs/.

\section{Literature Cited}

Agee, J. K., and S. C. F. Stitt. 1989. A geographic analysis of historical grizzly bear sightings in the north Cascades. Photogrammetric Engineering and Remote Sensing 55: 1637-1642.

Bales, S. L., E. C. Hellgren, D. M. Leslie, Jr., and J. Hemphill, Jr. 2005. Dynamics of a recolonizing population of black bears in the Ouachita Mountains of Oklahoma. Wildlife Society Bulletin 33: 1342-1351.

Boccadori, S. J., P. J. White, R. A. Garrott, J. J. Borkowski, and T. L. Davis. 2008. Yellowstone pronghorn alter resource selection after sagebrush decline. Journal of Mammalogy 89: 1031-1040.

Boyce, M. S., P. R.Vernier, S. E. Nielsen, and F. K. A. Schmiegelow. 2002. Evaluating resource selection functions. Ecological Modeling 157: 281-300.

Casey, C. B. 1972. Mirages, mysteries, and reality: Brewster County, Texas. Pioneer Book Publishers, Inc., Seagraves, Texas, USA.

Carroll, C., and D. G. Miquelle. 2006. Spatial viability analysis of Amur tiger Panthera tigris altaica in the Russian Far East: the role of protected areas and landscape matrix in population persistence. Journal of Applied Ecology 43: 1056-1068.

Ciarniello, L. M., M. S. Boyce, D. C. Heard, and D. R. Seip. 2007. Components of grizzly bear habitat selection: density, habitats, roads, and mortality risks. Journal of Wildlife Management 71: 1446-1457. 
Davis, F. W., D. M. Stoms, J. E. Estes, and J. Scepan. 1990. An information systems approach to the preservation of biological diversity. International Journal of Geographical Information Systems 4: 55-78.

Doan-Crider, D. L. 1995. Population characteristics and home range dynamics of a black bear population in northern Coahuila Mexico. Thesis, Texas A\&M University, Kingsville, Texas, USA.

Dugelby, B. L., D. Foreman, R. List, B. Miller, J. Humphrey, M. Siedman, and R. Howard. 2001. Rewilding the sky islands of the southwest. Pages 65-82 in Large Mammal Restoration: Ecological and Sociological Challenges in the 21st Century. Edited by M. E. Sunquist, D. S. Maehr, R. F. Noss, and J. L. Larkin. Island Press, Washington, D.C.

Fecske, D. M., R. E. Barry, F. L. Precht, H. B. Quigley, S. L. Bittner, and T. Webster. 2003. Habitat use by female black bears in western Maryland. Southeastern Naturalist 1: 77-92.

Garshelis, D. L., and M. R. Pelton. 1981. Movements of black bears in the Great Smoky Mountains National Park. Journal of Wildlife Management 45: 912-925.

Gehlbach, F. R. 1981. Mountain Islands and Desert Seas: a natural history of the U.S. Mexican borderlands. Texas A\&M University Press, College Station, Texas, USA.

Graf, R. F., K. Bollman, H. Bugmann, and W. Suter. 2007. Forest and landscape structure as predictors of Capercaillie occurrence. Journal of Wildlife Management 71: 356-365.

Guisan, A., and N. B. Zimmermann. 2000. Predictive habitat distribution models in ecology. Ecological Modelling 135: 147-186.

Harris, L. D., L. C. Duever, R. P. Meegan, T. S. Hoctor, J. L. Schortemeyer, and D. S. Maehr. 2001. The biotic province: minimum unit for conserving biodiversity. In Large Mammal Restoration: Ecological and Sociological Challenges in the 21 st Century. Edited by M. E. Sunquist, D. S. Maehr, R. F. Noss, and J. L. Larkin. Island Press, Washington, D.C.

Hellgren, E. C. 1993. Status, distribution, and summer food habits of black bears in Big Bend National Park. Southwestern Naturalist 38: 77-80.

Hellgren, E. C., M. R. Vaughn, and D. F. Stauffer. 1991. Macrohabitat use by black bears in a southeastern wetland. Journal of Wildlife Management 55: 442-448.

Hellgren, E. C., D. P, Onorato, and J. R. Skiles, Jr. 2005. Dynamics of a black bear population within a desert metapopulation. Biological Conservation 122: 131-140.

Johnson, C. J., M. S. Boyce, R. I. Case, H. D. Cluff, R. J. Gau, R. Gunn, and R. Mulders. 2005. Cumulative effects of human developments on arctic wildlife. Wildlife Monographs 160: 1-36.

Kamler, J. F., L. S. Green, and W. B. Ballard. 2003. Recent occurrence of black bears in the southwestern Great Plains. Southwestern Naturalist 43: 303-306.

Koehler, G. M., and D. J. Pierce. 2003. Black bear home range sizes in Washington: climatic, vegetative, and social influences. Journal of Mammalogy 84: 81-91.

Lantz, S. J., C. J. Conway, and S. H. Anderson. 2007. Multiscale habitat selection by burrowing owls in blacktailed prairie dog colonies. Journal of Wildlife Management 71: 2664-2672.

LeCount, A. L., and J. C. Yarchin. 1990. Black bear habitat use in east-central Arizona. Arizona Game and Fish Department Technical Report 4: 1-34.
Long, R. A., J. D. Muir, J. L. Rachlow, and J. G. Kie. 2009. A comparison of two modeling approaches for evaluating wildlife-habitat relationships. Journal of Wildlife Management 73: 294-302.

MacNally, R., E. Fleishman, L. P. Bullock, and C. J. Betrus. 2004. Comparative influence of spatial scale on beta diversity within regional assemblages of birds and butterflies. Journal of Biogeography 31: 917-929.

McCarthy, M. A. 2007. Bayesian Methods for Ecology. Cambridge University Press, Cambridge, UK.

Mitchell, M. S., J. W. Zimmerman, and R. A. Powell. 2002. Test of a habitat suitability index for black bears in the southern Appalachians. Wildlife Society Bulletin 30: 794808.

Mitchell, F. S., D. P. Onorato, E. C. Hellgren, J. R. Skiles, Jr., and L. A. Harveson. 2005. Winter ecology of American Black Bears in a desert montane island. Wildlife Society Bulletin 33: 164-171.

O'Neill, R. V., J. R. Krummel, R. H. Gardner, G. Sugihara, B. Jackson, D. L. DeAngelis, B. T. Milne, M. G. Turner, B. Zygmunt, B. Christensen, V. H. Dale, and R. L. Graham. 1988. Indices of landscape pattern. Landscape Ecology 1: 153-162.

Onorato, D. P., and E. C. Hellgren. 2001. Black bear at the border: natural recolonization of the Trans-Pecos. Pages 245-259 in Large Mammal Restoration: Ecological and Sociological Challenges in the $21^{\text {st }}$ Century. Edited by M. E. Sunquist, D. S. Maehr, R. F. Noss, and J. L. Larkin. Island Press, Washington, D.C.

Onorato, D. P., E. C. Hellgren, F. S. Mitchell, and J. R. Skiles, Jr. 2003. Home range and habitat use of American black bears on a desert montane island in Texas. Ursus 14: $120-129$.

Onorato, D. P., E. C. Hellgren, R. A. Van Den Bussche, and D. L. Doan-Crider. 2004. Phylogenetic patterns within a metapopulation of black bears (Ursus americanus) in the American southwest. Journal of Mammalogy 85: 140-147.

Palma, L., P. Beja, and M. Rodrigues. 1999. The use of sighting data to analyse Iberian lynx habitat and distribution. Journal of Applied Ecology 36: 812-824.

Pike, J. R., J. H. Shaw, D. M. Leslie, Jr., and M. G. Shaw. 1999. A geographic analysis of the status of mountain lions in Oklahoma. Wildlife Society Bulletin 27: 4-11.

Poirazidis, K., V. Goutner, T. Skartsi, and G. Stamou. 2004. Modelling nesting habitat as a conservation tool for the Eurasian black vulture (Aegypius monachus) in Dadia Nature Reserve, northeastern Greece. Biological Conservation 118: 235-248.

Powell, A. M. 1998. Trees and shrubs of the Trans-Pecos and adjacent areas. University of Texas Press, Texas, USA.

Queheillalt, D. M., and M. L. Morrison. 2006. Vertebrate use of a restored riparian site: a case study on the central coast of California. Journal of Wildlife Management 70: 859-866.

Rice, M. B. 2006. Landscape analysis of a recolonizing black bear population in the Trans-Pecos region of Texas. Dissertation, Texas Tech University, Lubbock, Texas, USA.

Rice, M. B., W. B. Ballard, E. B. Fish, N. E. McIntyre, and D. Holdermann. 2008. The importance of accurate landuse/landcover maps for assessing habitat utilization by black bear in the Trans-Pecos region of Texas. Wildlife Biology in Practice 4: 48-56.

Sanderson, E. W., K. H. Redford, B. Weber, K. Aune, D. Baldes, J. Berger, D. Carter, C. Curtin, J. Derr, S. 
Dobrott, E. Fearn, C. Fleener, S. Forrest, C. Gerlach, C. C. Gates, J. E. Gross, P. Gogan, S. Grassel, J. A. Hilty, M. Jensen, K. Kunkel, D. Lammers, R. List, K. Minkowski, T. Olson, C. Pague, P. B. Robertson, and B. Stephenson. 2008. The ecological future of the North American bison: conceiving long-term, large-scale conservation of wildlife. Conservation Biology 22: 252-266.

Schadt, S., F. Knauer, P. Kaczensky, E. Revilla, T. Wiegand, and L. Trepl. 2002. Rule-based assessment of suitable habitat and patch connectivity for the Eurasian lynx. Ecological Applications 12: 1469-1483.

Slauson, K. M., W. J. Zielinski, and J. P. Hayes. 2007. Habitat selection by American martens in coastal California. Journal of Wildlife Management 71: 458-468.

Steele, D. G. 1998. Land of the desert sun. Texas A\&M University Press, College Station, Texas, USA.

Stoms, D. M., F. W. Davis, C. B. Cogan, M. Proctor, B. W. Duncan, and J. Scepan. 1993. Geographic analysis of California condor sighting data. Conservation Biology 7: $148-159$.
Tucker, K., S. P. Rushton, R. A. Sanderson, E. B. Martin, and J. Blaiklock. 1997. Modelling bird distributions-a combined GIS and Bayesian rule-based approach. Landscape Ecology 12: 77-93.

VanDerWal, J., L. P. Shoo, C. Graham, and S. E. Williams. 2009. Selecting pseudo-absence data for presence-only distribution modeling: how far should you stray from what you know? Ecological Modeling 220: 589-594.

Whittaker, D. G., and A. G. Burns. 2001. Black bear status in western North America: summary of western state and province bear status report surveys. Western Black Bear Workshop 7: 32-55.

Wintle, B. A., M. A. McCarthy, C. T. Volinsky, and E. P. Kavanagh. 2003. The use of Bayesian model averaging to better represent uncertainty in ecological models. Conservation Biology 17: 1579-1590.

Woolf, A., C. K. Nielsen, T. Weber, and T. J. GibbsKieninger. 2002. Statewide modeling of bobcat, Lynx rufus, habitat in Illinois, USA. Biological Conservation 104: 191-198.

25 June 2009

Accepted 1 April 2010 